\title{
ESTUDO DA ADSORÇÃO DE SURFACTANTE CATIÔNICO NA MATRIZ INORGÂNICA FOSFATO DE NIÓBIO HIDRATADO
}

\author{
Paulo Henrique Fernandes Pereira e Maria Lucia C. P. da Silva* \\ Departamento de Engenharia Química, Escola de Engenharia de Lorena, Universidade de São Paulo, \\ CP 116, 12600-000 Lorena - SP, Brasil
}

Recebido em 25/7/07; aceito em 25/7/08; publicado na web em 18/12/08

\begin{abstract}
ADSORPTION STUDY OF THE SURFACTANT IN INORGANICS MATRICES. This work describes the study the adsorption of a cationic surfactant, cetyl trimethyl ammonium bromide (CTAB) in the hydrous niobium phosphate matrix. The matrix was characterized by powder X-ray diffraction (DRX), thermal analysis (TG), differential scanning calorimetry (DSC), scanning electron microscopy (SEM) and surface area measurements (BET). The Langmuir and Freundlich isothermal models were used in the CTAB adsorption study. The adsorption process wasn`t favorable for the $\mathrm{NbOPO}_{4} \cdot \mathrm{nH}_{2} \mathrm{O}$ in both studied models.
\end{abstract}

Keywords: Langmuir isotherm; Freundlich isotherm; hydrous niobium phosphate.

\section{INTRODUÇÃO}

O nióbio é encontrado na natureza nos minerais chamados columbita e pirocloro, cuja ocorrência na crosta terreste é da ordem de $24 \mathrm{~g} / \mathrm{t}$. O Brasil detém as maiores reservas de nióbio atualmente e é líder mundial na sua produção. ${ }^{1}$

O nióbio é um metal refratário ${ }^{2}$ com estrutura cúbica de corpo centrado, leve e dúctil ${ }^{3}$ que pode ser trabalhado e usinado quando não tiver impurezas. ${ }^{2}$ Apesar de resistente a vários ácidos, o nióbio metálico pode ser dissolvido em uma mistura de ácido fluorídrico/ nítrico. $^{4-8}$

O primeiro trabalho sobre métodos de preparação e processo de caracterização de fosfato de nióbio (V) foi realizado por Hahn, em 1951, utilizando quatro processos distintos: os dois primeiros partiram de óxido de nióbio (V) recém-precipitado; no terceiro, usou-se hexaniobato de potássio como material de partida e no quarto realizou-se fusão a $1000{ }^{\circ} \mathrm{C}$ de uma amostra de $\mathrm{Nb}_{2} \mathrm{O}_{5}$ previamente impregnada com excesso de ácido fosfórico (85\%). Um considerável número de compostos inorgânicos cristalino de características lamelares, tais como argilominerais, fosfatos, fosfanatos, óxidos de metais de transição etc, são conhecidos em virtude de suas diversas propriedades químicas, dentre elas destacam-se o comportamento de trocadores iônicos, adsorção e compostos de intercalação. ${ }^{9}$

No processo de adsorção as moléculas presentes na fase fluida são atraídas para a zona interfacial devido à existência de forças atrativas não compensadas na superfície do adsorvente. A adsorção em superfícies sólidas é uma tecnologia de separação e purificação, largamente utilizada em muitos processos industriais, que tem como objetivo concentrar substâncias. De acordo com a natureza do resíduo, orgânico ou inorgânico, o escoamento sem tratamento prévio em poços, lagoas, rios, mares ou oceanos tende gradualmente a ser proibido, pois além de potencialmente tóxico, pode reduzir níveis de oxigênio dissolvido impedindo o desenvolvimento da fauna e flora aquáticas. ${ }^{10}$

Os surfactantes são produtos muito utilizados nas indústrias químicas, aparecendo em uma série de segmentos, tais como em óleo de motor usados nos automóveis, em produtos farmacêuticos, em produtos de limpeza e processo de refino de petróleo. Na década passada houve uma

*e-mail: mlcaetano@ dequi.eel.usp.br grande expansão na aplicação de surfactantes nas áreas de tecnologia, impressão eletrônica, gravação magnética, microeletrônica, biotecnologia e pesquisa. ${ }^{11} \mathrm{~A}$ aplicação de surfactantes também pode produzir poluição ambiental e uma série de problemas nas plantas de tratamento de efluentes. ${ }^{11-13} \mathrm{O}$ processo de adsorção é usado em especial no tratamento de água e como adsorvente de baixo custo. Para determinação de surfatante são descritos diversos procedimentos baseados na utilização de métodos volumétricos, espectrofotométricos, cromatográficos, eletroforese capilar e potenciométricos. ${ }^{14,15} \mathrm{Um}$ surfactante é um composto orgânico que contém na mesma molécula dois grupos estruturais diferentes, um solúvel em água (grupo polar ou hidrofílico) e o outro insolúvel em água (grupo apolar ou hidrofóbico). Os surfactantes são classificados em aniônicos, catiônicos e não iônicos, de acordo com a ionização do seu grupo polar. ${ }^{16}$ Os grupos hidrofílicos em surfactantes catiônicos tornam-se carregados negativamente em solução aquosa como, por exemplo, o brometo de cetiltrimetilamônio.

A técnica de extração e quantificação de surfactantes é relativamente recente e tem despertado grande interesse no desenvolvimento de metodologia de adsorção para surfactantes em matrizes inorgânicas. Essa preocupação ambiental deve-se, em especial, aos efluentes oriundos de indústrias que utilizam esses compostos na sua fabricação.

Diversos materiais têm sido pesquisados como adsorventes para surfactantes, dos quais podem-se destacar os hidróxidos duplos lamelares, ${ }^{17}$ os argilomineriais, ${ }^{18-22}$ alguns polímeros ${ }^{23}$ e a celulose. ${ }^{24}$

Sheilam e Pinfold ${ }^{25}$ estudaram a determinação dos surfactantes catiônicos cloreto de dodecilpiridina, brometo de hexadecilpiridina e cloreto de hexadeciltrimetilamônio por extração do par iônico formado entre o ácido pícrico e o surfactante, utilizando como solvente de extração o 1,2-dicloroetano.

Segundo Rosen, ${ }^{11}$ a metodologia descrita por Sheilam e Pinfold ${ }^{25}$ se adequa a concentrações de surfactantes catiônicos de 10 a 100 mg $\mathrm{L}^{-1}$, com limite de detecção de $1 \mathrm{mg} \mathrm{L}^{-1}$.

Gurses et al. ${ }^{26}$ utilizaram a metodologia descrita por Sheilam e Pinfold ${ }^{25}$ para quantificar a adsorção, a $25^{\circ} \mathrm{C}$, de CTAB sobre carvão ativo em pó ( $900 \mathrm{~m}^{2} \mathrm{~g}^{-1}$ de área superficial específica), variando a concentração inicial do surfactante de 30 a $300 \mathrm{mg} \mathrm{L}^{-1}$ e o tempo de contato entre o material adsorvente e o surfactante.

Surfactantes catiônicos como cloreto de hexadecilpiridina (HDPC), brometo de cetiltrimetilamônio (CTAB), nitrato de tetrabutilamônio (TBAN) e hiamina formam pares iônicos com compostos orgânicos 
coloridos que contêm grupos ácidos sulfônicos. Além disso, estes pares iônicos são solúveis em diferentes solventes orgânicos como clorofórmio, tetracloreto de carbono, 1,2-dicloroetano e metil-isobutil-cetona (MIBK). A literatura enfatiza o uso do solvente 1,2-dicloroetano no processo de extração para quantificação de CTAB..$^{11,24,25}$

Com o intuito de desenvolver materiais com propriedades adequadas para serem usados como adsorvente, o Grupo de Novos Materiais da EEL/USP vem estudando a preparação de materiais com propriedades adequadas para adsorção de íons e moléculas em matrizes inorgânicas.

O objetivo desse trabalho foi preparar o fosfato de nióbio hidratado via nióbio metálico e, posteriormente, estudar a adsorção do surfactante catiônico (CTAB) na matriz inorgânica.

\section{PARTE EXPERIMENTAL}

Todos os reagentes utilizados eram de grau analítico (PA) e as soluções foram preparadas com água deionizada.

\section{Preparação do $\mathrm{NbOPO}_{4} \cdot \mathrm{nH}_{2} \mathrm{O}$}

O fosfato de nióbio hidratado foi preparado pela dissolução do nióbio metálico, usando-se um béquer de polietileno com uma mistura de ácido fluorídrico (40\%) e ácido nítrico concentrado na proporção (10:1). Após dissolução adicionou-se ácido fosfórico concentrado e a solução foi colocada para concentrar em banho-maria durante $34 \mathrm{~h}$ na temperatura de aproximadamente $60{ }^{\circ} \mathrm{C}$. Formou-se um precipitado branco gelatinoso que foi lavado com ácido nítrico $\left(5 \mathrm{~mol} \mathrm{~L}^{-1}\right)$, água deionizada e etanol e secado a $50{ }^{\circ} \mathrm{C}$ até peso constante.

\section{Caracterização do $\mathrm{NbOPO}_{4} \cdot \mathrm{nH}_{2} \mathrm{O}$ e do material adsorvido com CTAB}

O material preparado foi caracterizado por difração de raios-X (DRX), termogravimetria (TG) e calorimetria exploratória diferencial (DSC), microscopia eletrônica de varredura (MEV) acoplada ao espectrômetro de energia dispersiva (EDS) e medida de área superficial específica pelo método BET. O material preparado foi analisado num difratômetro marca Rich Seifert, com fonte de radiação $\mathrm{CuK}$ variando-se 2 entre 10 e $70^{\circ}$. A medida de termogravimetria foi efetuada em cadinho de platina aberto, com razão de aquecimento de $20{ }^{\circ} \mathrm{C}$ $\min ^{-1}$ com fluxo de $\mathrm{N}_{2}$ (g) de $50 \mathrm{~mL} \mathrm{~min}^{-1}$, numa faixa de temperatura entre a temperatura ambiente e $900{ }^{\circ} \mathrm{C}$. Análises por calorimetria exploratória diferencial (DSC) foram feitas em um calorímetro da marca DP Union, aquecendo-se cerca de $5 \mathrm{mg}$ da amostra na faixa de temperatura de $25 \mathrm{a} 550{ }^{\circ} \mathrm{C}$, sob atmosfera de nitrogênio à uma razão de aquecimento de $10{ }^{\circ} \mathrm{C} \mathrm{min}^{-1}$, usando-se como padrão índio (In). Essa análise serve para determinar as energias envolvidas no processo. A fotomicrografia para o fosfato de nióbio hidratado foi obtida em um microscópio eletrônico de varredura (MEV) LEO modelo 1450VP usando elétrons secundários, sendo a amostra coberta com uma fina camada de ouro, e sua superfície micrografada com aumento de 2000 vezes. A medida de área superficial específica da amostra foi determinada em um analisador de adsorção gasosa (Gas Scorption Analiser) ChemBET-300 da Quantachrome Corporation, por meio de medidas de adsorção em atmosfera de nitrogênio. As condições de pré-tratamento foram de $50{ }^{\circ} \mathrm{C}$ por $16 \mathrm{~h}$ em estufa a vácuo.

\section{Determinação do tempo de agitação para adsorção do surfactante CTAB na matriz inorgânica}

Na determinação do parâmetro tempo de contato para definição do equilíbrio, pesou-se em um frasco de polietileno aproximadamente
$0,15 \mathrm{~g}$ de fosfato de nióbio hidratado e adicionou-se $50 \mathrm{~mL}$ de uma solução de CTAB (30 $\mathrm{mg} \mathrm{L}^{-1}$ ) levando-se em seguida para uma mesa de agitação. Após este tempo, o material foi filtrado em funil de Büchner e seco a $50{ }^{\circ} \mathrm{C}$. Realizaram-se experimentos com tempo de agitação de 1, 3, 5 e $7 \mathrm{~h}$.

\section{Estudo da adsorção do surfactante CTAB na matriz inorgânica}

O estudo da remoção do surfactante quaternário de amônio CTAB foi realizado utilizando-se o processo batelada, colocando em contato aproximadamente $0,15 \mathrm{~g}$ do fosfato de nióbio hidratado com $50 \mathrm{~mL}$ do surfactante em concentrações de 20, 24, 30, 34, $40 \mathrm{mg} \mathrm{L}^{-1}$, por 1 h. Os resultados obtidos foram analisados utilizando-se os modelos de Langmuir e de Freundlich, que são os mais freqüentemente utilizados na literatura. ${ }^{27,28}$

Para quantificação do surfactante, em $12 \mathrm{~mL}$ de CTAB adicionouse 0,24 $\mathrm{mL}$ de ácido pícrico em $\mathrm{NaOH} 0,002 \mathrm{~mol} / \mathrm{L} \mathrm{e}$, em seguida, colocou-se $6,00 \mathrm{~mL}$ do solvente metil-isobutil-cetona (MIBK). Agitou-se a mistura por 5 min para a completa extração do par iônico formado e separou-se a fase orgânica com centrifugação a $3500 \mathrm{rpm}$ durante $5 \mathrm{~min}$. Para determinação da concentração do CTAB usou-se um espectrofotômetro UV-visível, medindo-se a absorbância da fase orgânica a 375 nm, contra uma curva de calibração.

\section{RESULTADOS E DISCUSSÃO}

A difração de raios-X do pó (DRX) é um método de identificação das fases presentes em um material. Nesta análise, os materiais com arranjo cristalino ordenado e repetitivo apresentam difratogramas contendo picos de difração definidos.

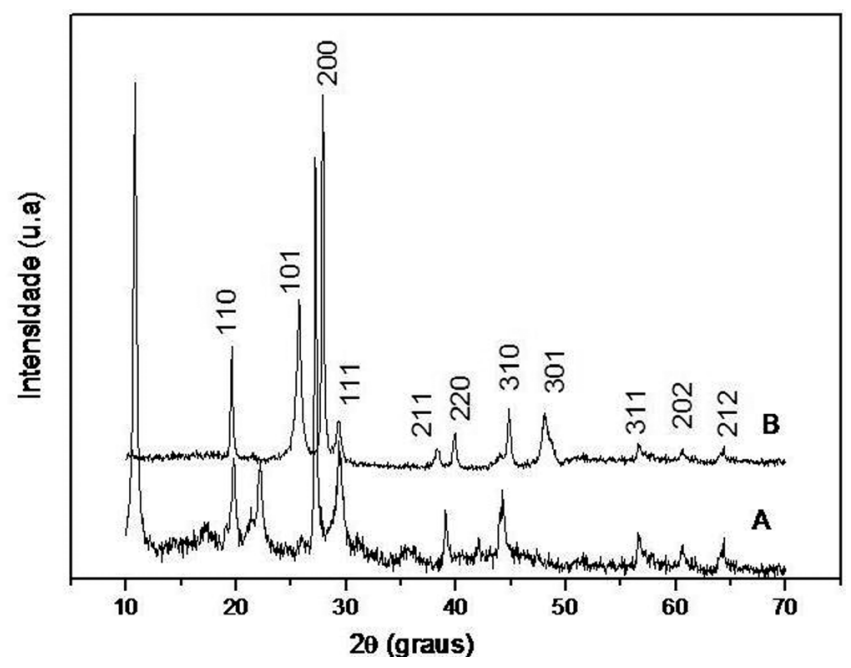

Figura 1. Difratograma de raios- $X$ do fosfato de nióbio hidratado (A) e do fosfato de nióbio desidratado (B) a $600{ }^{\circ} \mathrm{C}$

A Figura 1 apresenta os difratogramas de raios-X do fosfato de nióbio hidratado (A) e do fosfato de nióbio desidratado (B) a $600{ }^{\circ} \mathrm{C}$. Pode-se observar que o fosfato de nióbio hidratado apresenta difratograma com picos bem definidos. A Figura 1A apresenta reflexões abaixo de $20^{\circ}$. A literatura apresenta uma variedade de trabalhos cujos materiais inorgânicos apresentam picos nos difratogramas abaixo da região de $20^{\circ} .^{29,30}$ Esses picos podem ser decorrentes das distâncias entre as lamelas, o que torna possível a utilização desses materiais em processos de troca iônica, intercalação e pilarização. ${ }^{31,32}$

Como na literatura não existe a microficha catalográfica do fosfato de nióbio hidratado, procedeu-se à desidratação do material em mufla 
a $600{ }^{\circ} \mathrm{C}$ por $6 \mathrm{~h}$, para retirar as águas existentes e transformá-lo em fosfato de nióbio anidro. Com o material desidratado fez-se nova análise de difração de raios-X (DRX), calcularam-se as novas distâncias interplanares e posteriormente comparou-se com a microficha do $\mathrm{NbOPO}_{4}$ existente (JCPDS 19-866), confirmando a obtenção do $\mathrm{NbOPO}_{4}$ (anidro) após o tratamento térmico. Observa-se o desaparecimento da primeira reflexão (Figura 1A para 1B), abaixo de $20^{\circ}$ após o tratamento térmico devido à evaporação das moléculas de água existente entre as lamelas, o que proporcionou o colapso total da fase hidratada estável, eliminando a distância basal existente. ${ }^{5,21} \mathrm{O}$ método de Gauss é uma ferramenta matemática importante na interpretação das reflexões presentes nos difratogramas de raios-X. Através deste modelo, determina-se o ângulo de 2 representativo de cada reflexão. Fez-se o ajuste dos pontos experimentais e calculou-se a distância interplanar "d", Figura 1(A), cujo resultado é de 8,21 Å. O valor experimental é concordante com valor encontrado na literatura. ${ }^{33}$ Todo procedimento foi feito com auxílio do programa Origin 6.0.

A área superficial específica encontrada para o fosfato de nióbio hidratado foi de $8 \mathrm{~m}^{2} / \mathrm{g}$.

A análise por MEV do fosfato de nióbio hidratado (Figura 2) mostra um material formado com aglomerados porosos.

A Figura 3 mostra a curva TG do fosfato de nióbio hidratado.

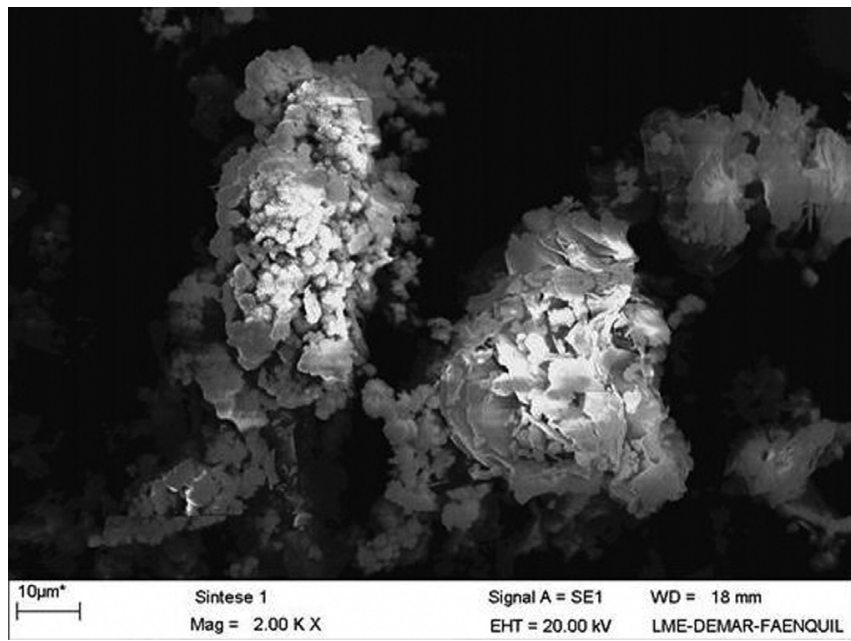

Figura 2. Micrografia do fosfato de nióbio hidratado obtida via elétrons secundários em microscópio eletrônico com ampliação de $2000 X$

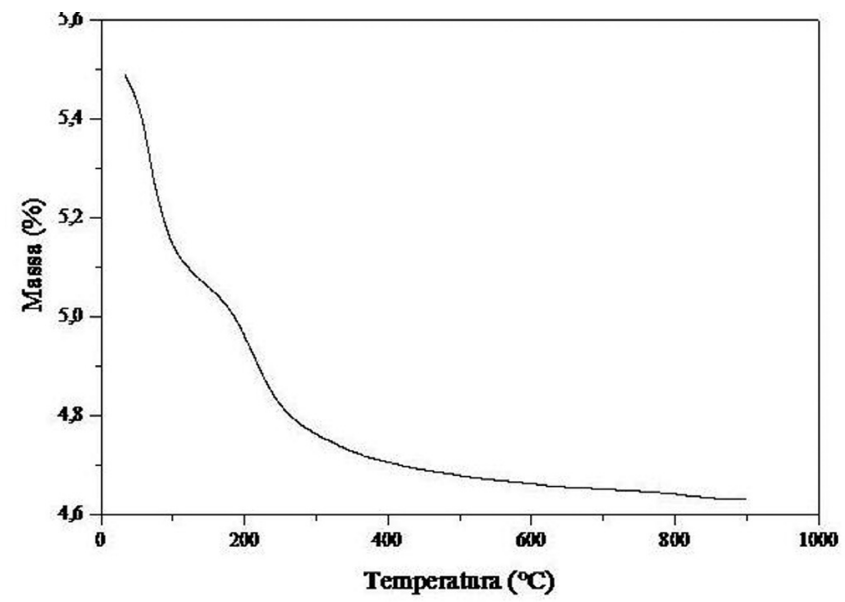

A termogravimetria foi utilizada para determinar o grau de hidratação n e a estabilidade térmica do material preparado. Esse estudo é importante, porque o grau de hidratação corresponde aos sítios ativos de troca iônica que, conseqüentemente, podem influenciar na sua capacidade de troca iônica. ${ }^{5,34,35}$

A curva TG do fosfato de nióbio hidratado (Figura 3) apresenta perda de massa ocorrendo em duas etapas distintas no intervalo temperatura entre 25 e $550{ }^{\circ} \mathrm{C}$. Na primeira etapa, entre 25 e $170{ }^{\circ} \mathrm{C}$, houve perda de massa devido à eliminação das moléculas de água mais fracamente ligadas, enquanto que na segunda etapa, entre 170 e $550^{\circ} \mathrm{C}$, houve eliminação das moléculas de água mais fortemente ligadas à estrutura da matriz. ${ }^{5}$

A fórmula estequiométrica para o fosfato de nióbio hidratado pode ser determinada considerando-se a perda total de água apresentada pela curva TG, no intervalo de temperatura de 25 a $550{ }^{\circ} \mathrm{C}$, efetuando-se os cálculos ${ }^{5}$ através da Equação 1.

$18 \mathrm{n}=\mathrm{X}(\mathrm{M}+18 \mathrm{n}) / 100$

sendo $\mathrm{X}=$ porcentagem de massa de água perdida; $\mathrm{n}=$ número de molécula de água e $\mathrm{M}=$ massa molecular do fosfato resultante da análise térmica, determina-se o valor do grau de hidratação (n) para o material preparado e, conseqüentemente, a sua fórmula estequiométrica. Este resultado encontra-se na Tabela 1, juntamente com os dados obtidos pelas curvas TG (Figura 3). A fórmula estequiométrica para o material preparado é $\mathrm{NbOPO}_{4} \cdot 2,0 \mathrm{H}_{2} \mathrm{O}$.

A curva DSC do fosfato de nióbio hidratado (Figura 4) apresenta dois picos endotérmicos, o primeiro na temperatura de $131^{\circ} \mathrm{C}$ e o segundo em $278^{\circ} \mathrm{C}$, ambos relativos à entalpia de desidratação do material, que ocorre em duas etapas. Uma primeira desidratação relativa à perda de moléculas de água que estão aprisionadas nos espaços interlamelares e ligadas por pontes de hidrogênio com os oxigênios presentes nas superfícies das la-

Tabela 1. Resultados das curvas TG/DTG obtidas para o fosfato de nióbio hidratado com as temperaturas correspondentes à velocidade máxima de perda de massa na curva DTG (dm), nos respectivos intervalos de temperatura $(\Delta \mathrm{T})$, com perdas de massa na curva TG (mp) grau de hidratação (n) e resíduo (R)

\begin{tabular}{lccccc}
\hline Material & $\Delta \mathrm{T}\left({ }^{\circ} \mathrm{C}\right)$ & $\% \mathrm{mp}$ & $\mathrm{dm}\left({ }^{\circ} \mathrm{C}\right)$ & $(\mathrm{n})$ & $\mathrm{R}(\%)$ \\
\hline & $\mathrm{Tamb}-170$ & 7,09 & 68 & & \\
$\mathrm{NbOPO}_{4} \cdot \mathrm{nH}_{2} \mathrm{O}$ & $\begin{array}{c}7,59 \\
170-550\end{array}$ & 213 & 2,0 & 85,32 \\
& & $\Sigma=14,68$ & & & \\
\hline
\end{tabular}

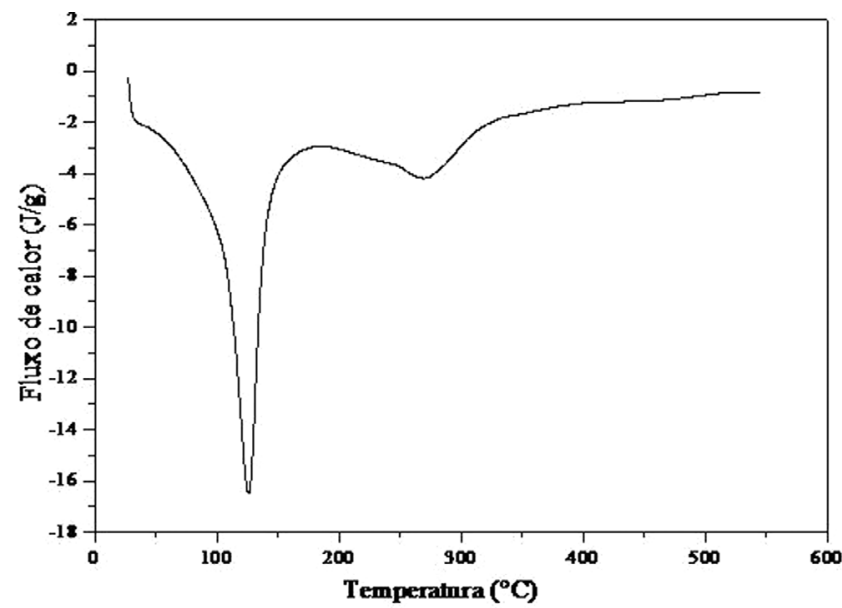

Figura 4. Curva de DSC do fosfato de nióbio hidratado 
melas. O segundo pico endotérmico indica a eliminação de moléculas de água reticular mais fortemente ligadas ao sólido, cujo oxigênio pertence ao poliedro de coordenação dos átomos de nióbio. ${ }^{36}$

\section{Determinação do tempo de contato entre a solução de CTAB e a matriz inorgânica}

No estudo de adsorção é importante conhecer o tempo necessário de contato entre a solução contendo a espécie a ser adsorvida e o material adsorvente para que se obtenha a maior eficiência de adsorção ou de remoção do íon.

Tabela 2. Quantidade (qe) de $\mathrm{CTA}^{+}$adsorvida na matriz inorgânica, para diferentes tempos (t) de agitação

\begin{tabular}{lcccc}
\hline $\mathrm{t}(\mathrm{h})$ & 1 & 3 & 5 & 7 \\
\hline Qe $\left(\mathrm{mg} \mathrm{g}^{-1}\right)$ & 8,58 & 7,91 & 7,59 & 8,04 \\
\hline
\end{tabular}

Por meio dos dados obtidos na Tabela 2 verificou-se que houve maior adsorção do surfactante para o tempo de agitação de $1 \mathrm{~h}$, com adsorção de 8,58 mg de surfactante/g de fosfato de nióbio hidratado. Assim, foi fixado o tempo de $1 \mathrm{~h}$ para os experimentos realizados para o estudo de adsorção.

\section{Isotermas de adsorção}

As isotermas de adsorção foram determinadas para o sistema surfactante/fosfato de nióbio hidratado usando as equações de Langmuir e de Freundlich, que são os modelos mais freqüentemente usados para descrever isotermas para aplicações em tratamento de água e efluentes. ${ }^{27}$ As Figuras 5 e 6 mostram as formas linearizadas das Equações de Langmuir e Freundlich obtidas dos dados de adsorção do fosfato de nióbio hidratado como surfactante catiônico CTAB. As Equações de Langmuir e de Freundlich podem ser linearizadas e as constantes podem ser determinadas. ${ }^{28}$

A expressão linear de Langmuir é:

$$
\mathrm{C}_{\mathrm{e}} / \mathrm{qe}=1 / \mathrm{Q}_{0} \cdot \mathrm{b}+\mathrm{C}_{\mathrm{e}} / \mathrm{Q}_{0}
$$

sendo $C_{e}$ a concentração do surfactante no equilíbrio $\left(\mathrm{mg} \mathrm{L}^{-1}\right), q_{e}$ a quantidade adsorvida no equilíbrio $\left(\mathrm{mg} \mathrm{g}^{-1}\right), Q_{0}\left(\mathrm{mg} \mathrm{g}^{-1}\right)$ e $b\left(\mathrm{~L} \mathrm{mg}^{-1}\right)$ constantes relacionadas com a capacidade de adsorção máxima e energia de adsorção, respectivamente.

$\mathrm{O}$ gráfico linear de $\mathrm{C}_{\mathrm{e}} / \mathrm{q}_{\mathrm{e}} \vee \mathrm{C}_{\mathrm{e}}$ confirma a validade do modelo de Langmuir para o processo. A equação de reta obtida apresentará coeficiente angular correspondente a $1 / \mathrm{Q}_{0}$ e coeficiente linear correspondente a $1 /\left(\mathrm{Q}_{0} \cdot \mathrm{b}\right)$. A característica essencial da isoterma pode ser expressa pela constante adimensional chamada parâmetro de equilíbrio, o qual é definido como:

$\mathrm{R}_{\mathrm{L}}=1 /\left(1+\mathrm{b} . \mathrm{C}_{0}\right)$

sendo $\mathrm{C}_{0}$ a concentração inicial do surfactante mais alta (mg.L $\left.\mathrm{L}^{-1}\right)$ e $b$ a constante de Langmuir. $\mathrm{O}$ valor de $R_{L}$ entre 0 e 1 indica adsorção favorável.
A forma linear da Equação de Freundlich é dada pela equação:

$\log \mathrm{q}_{\mathrm{e}}=\log \mathrm{K}_{\mathrm{f}}+1 / \mathrm{n} \log \mathrm{C}_{\mathrm{e}}$

sendo $\mathrm{K}_{\mathrm{f}}\left(\mathrm{mg} \mathrm{g}^{-1}\right)$ e $\mathrm{n}$ constantes relacionadas com a capacidade de adsorção e a intensidade de adsorção, respectivamente. $\mathrm{O}$ valor de $\mathrm{n}$ entre 2 e 10 indica processo de adsorção favorável.

Com os resultados das isotermas calcularam-se os parâmetros de adsorção do íon $\mathrm{CTA}^{+}$no fosfato de nióbio hidratado (Tabela 3). As constantes de Langmuir foram determinadas por regressão linear de Ce/qe versus Ce e log qe versus log Ce para Freundlich.

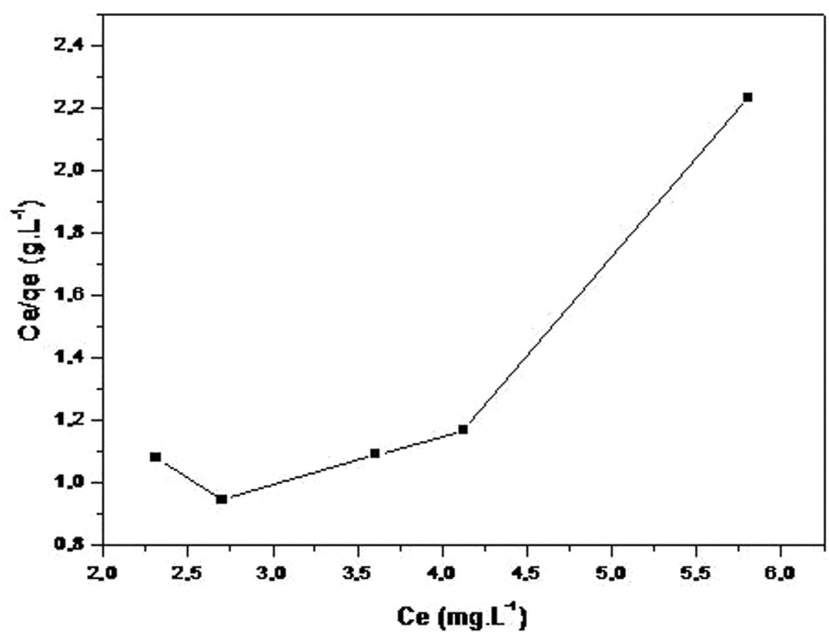

Figura 5. Forma linearizada da isoterma de adsorção do $\mathrm{CTA}^{+}$, em pH 5,6 pelo modelo de Langmuir utilizando como adsorvente o fosfato de nióbio hidratado

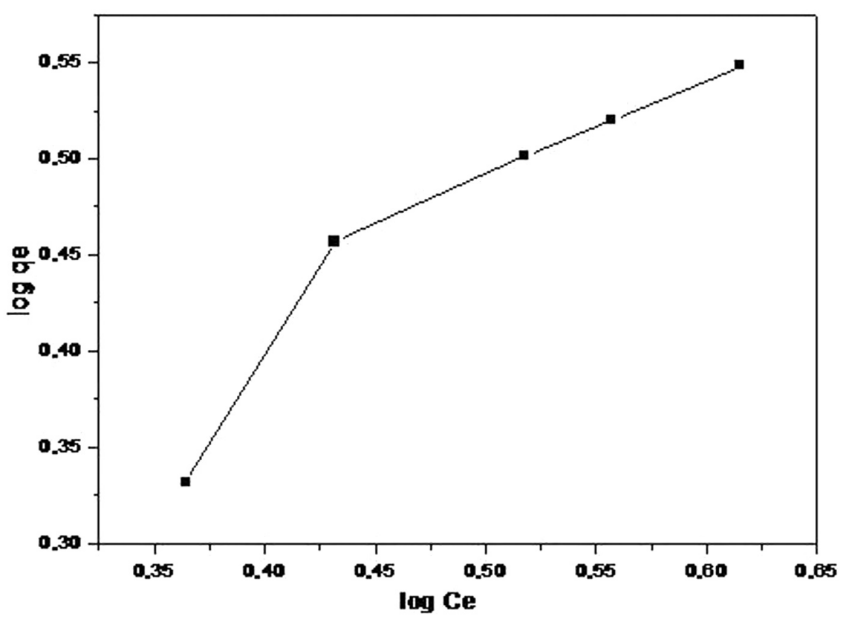

Figura 6. Forma linearizada da isoterma de adsorção do $\mathrm{CTA}^{+}$, em pH 5,6 pelo modelo de Freundlich, utilizando como adsorvente o fosfato de nióbio hidratado

Tabela 3. Parâmetros das isotermas, do modelo de Langmuir e de Freundlich para o íon $\mathrm{CTA}^{+}$, utilizando como adsorvente o $\mathrm{NbOPO}_{4} \cdot \mathrm{nH}_{2} \mathrm{O}$, em $\mathrm{pH} 5,6$

\begin{tabular}{lccccccc}
\hline $\mathrm{NbOPO}_{4} \cdot \mathrm{nH}_{2} \mathrm{O}$ & \multicolumn{3}{c}{ Langmuir } & \multicolumn{3}{c}{ Freundlich } \\
& $\mathrm{Q}_{\mathrm{o}}\left(\mathrm{mg} \mathrm{g}^{-1}\right)$ & $\mathrm{b}\left(\mathrm{L} \mathrm{mg}^{-1}\right)$ & $\mathrm{R}_{\mathrm{L}}$ & $\mathrm{R}^{2}$ & $\mathrm{~K}_{\mathrm{F}}\left(\mathrm{mg} \mathrm{g}^{-1}\right)$ & $\mathrm{n}$ & $\mathrm{R}^{2}$ \\
\hline $\mathrm{pH} \mathrm{5,6}$ & 2,908 & 12,797 & 0,0185 & 0,896 & 1,191 & 1,273 & 0,954 \\
\hline
\end{tabular}


Observa-se pelas Figuras 5 e 6 e pelos dados da Tabela 3 que os modelos de Langmuir e de Freundlich não se ajustam aos dados experimentais, para a adsorção do íon $\mathrm{CTA}^{+}$no fosfato de nióbio em pH 5,6.

Estudou-se o efeito do $\mathrm{pH}$ na matriz, corrigindo-se a solução de $\mathrm{CTAB}$ para $\mathrm{pH} 3$ e $\mathrm{pH}$ 9. Estudou-se também a eficiência do processo de adsorção com pré-intercalação de íons sódio no sistema e os dados obtidos não foram satisfatórios. As curvas determinadas mostraram que o sistema não se ajusta aos modelos de Langmuir e de Freundlich nos $\mathrm{pH}$ 's estudados.

\section{CONCLUSÃO}

Os resultados de DRX mostram a formação do NbOPO4 a 600 ${ }^{\circ} \mathrm{C}$, comportando-se como material cristalino. Os resultados de TG e DSC são concordantes e revelam a existência de dois tipos de água ligadas à matriz inorgânica.

O material preparado apresentou-se de forma organizada com características adequadas para aplicação como adsorvente. A fórmula estequiométrica para o produto é $\mathrm{NbOPO}_{4} \cdot 2,0 \mathrm{H}_{2} \mathrm{O}$.

No processo de adsorção com CTAB, o fosfato de nióbio hidratado apresentou-se como um bom adsorvente, porém não se ajustou aos modelos de Langmuir e de Freundlich.

\section{AGRADECIMENTOS}

Ao apoio financeiro do Capes pela bolsa concedida.

\section{REFERÊNCIAS}

1. http://www.cbmm.com.br/portug/surces/usesf-uses.htm, acessada em Maio 2007.

2. Aggarwal, G.; Park, S. J.; Smid, I.; Int. J. Refract. Met. Hard Mater. 2006, 24, 253

3. Aggarwal, G.; Smid, I.; Park, S. J. German, R. M.; Int. J. Refract. Met. Hard Mater. 2007, 25, 226.

4. Bayot, D.; Devillers, M.; Coord. Chem. Rev. 2006, 250, 2610.

5. Tagliaferro, G. V.; Silva, M. L. C. P.; Silva, G. L. P.; Quim. Nova 2005, 28,250

6. Villela, D. N. Filho; Silva, G. L. P.; Silva, M. L. C. P.; Mater. Res. 2002 5,71 .

7. Bruque, S.; Martinez Lara, M.; Moreno-Real, L.; Jimenez- Lopez, A.; Casal, B.; Ruiz - Hitzky, E.; Sanz, J.; Inorg. Chem. 1986, 26, 847.

8. Hanh, R. B.; J. Am. Chem. Soc. 1951, 73, 5091.

9. Clearfield, A.; Inorganic Ion Exchange Materials, CRC Press: Boca Raton, 1982
10. Ahmaruzzaman, M.; Sharma, D. K.; J. Colloid Interface Sci. 2005, 287, 14.

11. Rosen, M. J.; Li, F.; Morral, S. W.; Versteeg, D. J.; Environ. Sci. Technol. 2001, 35, 954

12. Paxeus, N.; Water Res. 1996, 30, 1115 .

13. Jönsson, B.; Lindman, B.; Holmberg, K.; Kronberg, B.; Surfactants and Polymers in Aqueous Solutroneds, John Wiley \& Sons: New York, 1998.

14. Baptista, P. C. S.; Araújo, A. N.; Montenegro, M. C. B. S. M. D.; Quim. Nova 2003, 26, 475 .

15. Cserháti, T.; Forgács, E.; Oros, G.; Environ. Rev. 2002, 28, 337.

16. Cross, J. E.; Surfactant Science, $8^{\text {th }}$ ed., Marcel Dekker: New York,1997.

17. You, Y.; Zhao, H.; Vance. G. F.; Colloids Surf., A 2002, 205, 161.

18. Ghiaci, M.; Kalbasi, R. J.; Khani, H.; Abbaspur, A.; Sharia, T.; J. Chem. Thermodynamics 2004, 36, 707.

19. Klumpp, E.; Contreras-Ortega, C.; Klahre, P.; Tino, F. J.; Yapar, S.; Portillo, C.; Stegen, S.; Queirolo, F.; Schwuger, M. J.; Colloids Surf., A 2004, 230, 111.

20. Gardolinski, J. E.; Wypych, F.; Quim. Nova 2001, 24, 761.

21. Gardolinski, J. E.; Martins Filho, H. P.; Wypych, F.; Quim. Nova 2003, $26,35$.

22. Wypych, F.; Arízaga G. G. C.; Quim. Nova 2005, 28, 24.

23. Otsuka ,H.; Esumi; K.; Colloid Interface Sci. 1995, 170, 113.

24. Yamanaka, Y.; Esumi K.; Colloids Surf., A 1997, 122, 121.

25. Sheiham, I.; Pinfold, T. A.; Analyst 1969, 94, 388.

26. Gurses, A.; Yalcin, M.; Sozbilir, M.; Dogar, C.; Fuel Process. Technol. 2003, 81, 57.

27. Fungaro, D. A.; Silva, M. G.; Quim. Nova 2002, 25, 1081.

28. Fungaro, D. A.; Izidoro, J. C.; Quim. Nova 2006, 29, 735.

29. Nunes, L. M.; Airoldi, C.; Quim. Nova 2001, 24, 799.

30. Domen, K.; Ebina, Y.; Ikeda, S.; Tanaka, A.; Kondo, J. N.; Maruya, K.; Catal. Today 1996, 28, 167.

31. Farias, R. F.; Airoldi, C.; J. Solid State Chem. 2002, 166, 277.

32. Guimarães, J. L.; Dissertação de Mestrado, Universidade Federal do Paraná, Brasil, 2002.

33. Longo, J. M.; Kierkegaard, R. D. P.; Acta Chemica Scandinavica 1966 , $20,78$.

34. Inoue, Y.; Yamazaki, H.; Kimura, Y.; Bull. Chem. Soc. Jpn. 1985, 58, 2481.

35. Inoue, Y.; Yamazaki, H.; Ikeda, M.; Bull. Chem. Soc. Jpn. 1989, 62, 262.

36. Antunes, C. A.; Folgueras-Dominguez, S.; Quim. Nova 1993, 16, 521. 